Casos Clínicos

Arch. Esp. Urol., 59, 5 (530-532), 2006

\section{METÁSTASIS DE CARCINOMA RENAL EN CUERPO CAVERNOSO, A PROPÓSITO DE UN CASO Y REVISIÓN DE LA LITERATURA.}

\author{
Estefanía Romero Selas, C. Lamas Meilán, Alfonso \\ Barbagelata López, José Luis Ponce Díaz-Reixa, \\ Enrique Fernández Rosado, Luis Álvarez Castelo, \\ Dolores Rey Fraga, Manuel Montes Coucedo, Manuel \\ Ruibal Moldes, S. Novás Castro, Venancio Chantada \\ Abal y Marcelino González Martín.
}

Servicio de Urología. Hospital Juan Canalejo. La Coruña. España

Resumen.- OBJETIVO: Describimos un caso infrecuente, la metástasis en cuerpo cavernoso de un carcinoma renal de células claras.

MÉTODOS: Se trata de un paciente de 53 años, que a los tres meses tras realizarle nefrectomía radical derecha con cavotomía y exéresis de trombo, presenta una tumoración localizada en pene, indurada y dolorosa.

RESULTADOS/CONCLUSIONES: Con pruebas de imagen y biopsia, se llegó al diagnóstico de metástasis de carcinoma renal en cuerpo cavernoso que se confirmó con la anatomía patológica de la pieza tras penectomía. La aparición de metástasis de carcinoma renal en pene está generalmente asociada a un estadio avanzado del tumor y por lo tanto, con mal pronóstico, como el caso relatado.

Palabras clave: Metástasis. Carcinoma renal. Cuerpo cavernoso.

Estefanía Romero Selas

Secretaría de Urología Planta 11

Hospital Juan Canalejo

Xubias de Arriba, 84

15006 La Coruña. (España)

eromeroselas@yahoo.es

Trabajo recibido: 19 de septiembre 2005
Summary.- OBJECTIVE: We describe a rare case, the metastasis of a renal clear cell carcinoma in the corpora cavernosum of the penis.

METHODS: 53-year-old patient presenting with a painful, hard tumor in the penis three months after right radical nephrectomy with cavotomy and thrombus excision.

RESULTS/ CONCLUSIONS: Imaging tests and biopsy led to the diagnosis of metastasis of a renal carcinoma in the corpus cavernosum, which was confirmed on the pathologic study of the specimen after penectomy. The appearance of renal carcinoma metastases in the penis is generally associated with advanced tumor stage, therefore associated with bad prognosis as in the reported case.

Keywords: Metastasis. Renal carcinoma. Corpora cavernosum.

\section{INTRODUCCIÓN}

El estadio del tumor es el factor pronóstico más importante, a pesar de que el carcinoma renal se caracteriza por un comportamiento errático de sus metástasis. Un $25 \%$ presentan metástasis en el momento del diagnóstico, siendo las más frecuentes las pulmonares, óseas y hepáticas. En cambio, a pesar de la rica vascularización y drenaje linfático abundante que posee el pene, la afectación metastásica es poco habitual, asociada a un estadio avanzado del tumor y con un mal pronóstico.

En el caso que presentamos a continuación la manifestación inicial del tumor fue derivada de un estadio avanzado del mismo.

\section{CASO CLÍNICO}

Se trata de un varón de 53 años sin antecedentes de interés que ingresa procedente de urgencias con un cuadro de tromboembolismo pulmonar.

Ante la sospecha de neoplasia oculta y la presencia de hematuria no evidenciada previamente se procede a la realización de Ecografía abdominal donde se evidencia una masa renal derecha y se completa el estudio con TAC y RM. (Figura 1).

Ambos estudios confirman la presencia de una tumoración heterogénea que infiltra los dos tercios inferiores del riñón derecho de aproximadamente $10 \times 10 \mathrm{cms}$. con afectación del seno e hilio renal objetivándose también trombosis tumoral de la vena renal derecha y cava infrahepática. No se evidenciaban adenopatías ni metástasis. 
Es intervenido quirúrgicamente realizándosele por vía anterior, una nefrectomía radical con cavotomía para la exéresis del trombo y una extensa linfadenectomía aorto-cava derecha.

El resultado anatomo-patológico fue de carcinoma de células renales claras grado 2 de Fuhrman de $9 \mathrm{~cm}$. con invasión de hilio renal, grasa perinéfrica y vena renal, sin afectación metastásica de ganglios ni de los bordes de dicha grasa ni del hilio, así como uréter libres. (Estadio III, T3NOMO). El paciente fue dado de alta hospitalaria al sexto día.

A los 3 meses de la intervención el paciente refiere leve dolor e induración en el pene de reciente aparición. A la palpación se objetiva una masa indurada.

Se le realiza RM de pelvis que nos informa de la existencia de una masa que ocupa y expande el cuerpo cavernoso izquierdo, compatible con metástasis de carcinoma renal previo. (Figura 2).

Se toma biopsia de dicha lesión, cuyo resultado nos confirma la sospecha evidenciándose en los cortes histológicos nidos aislados de células tumorales compatibles con metástasis de carcinoma de células claras.

Ante este diagnóstico, nos planteamos cuál sería la mejor actitud terapéutica para el paciente, y tuvimos en cuenta para ello, el incremento progresivo del dolor local, la edad del paciente y su buen estado general. Por ello, se optó por una penectomía total hasta confirmar intraoperatoriamente un borde quirúrgico libre de enfermedad.

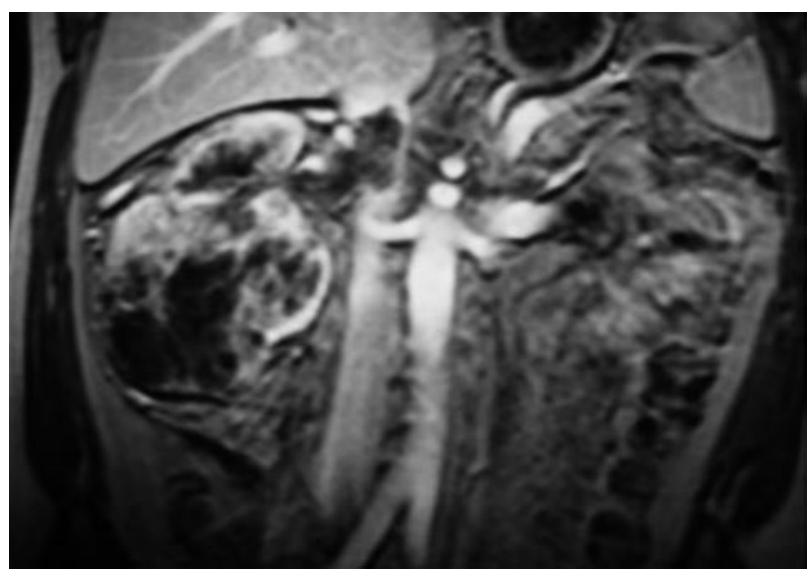

FIGURA 1. Imagen de RM en la que se aprecia una masa en el polo inferior del riñón derecho de 10x 10 centímetros con áreas hipo e hiperintensas en T2 que realzan de forma heterogénea tras la administración de gadolinio, la cual es compatible con carcinoma renal con áreas de necrosis en su interior. También se puede apreciar la imagen de un trombo oclusivo en la vena renal y no oclusivo en la vena cava inferior.
Una semana después del alta ingresa en el servicio de Oncología con un cuadro de obnubilación y alteración motora y sensitiva, y presenta en el TC craneal lesiones en cerebelo y hemisferio cerebral derecho compatible con metástasis. Se realiza un TC torácico y aparecen también múltiples nódulos pulmonares y microadenopatías paratraqueales bilaterales en relación con metástasis.

El paciente fallece a los nueve meses de la primera intervención de su carcinoma renal, es decir seis meses después del diagnóstico de las metástasis en pene.

\section{DISCUSIÓN}

Las metástasis peneanas procedentes de cualquier carcinoma son poco frecuentes e indicativas de mal pronóstico. Esta infrecuencia es sorprendente, si se considera el rico aporte sanguíneo y linfático del órgano, así como las abundantes interconexiones que el pene mantiene con órganos pélvicos próximos. Algunos autores dan como explicación a esto, la escasa atención que se le presta a este órgano en las exploraciones clínicas o en las necropsias, y otros defienden un posible mecanismo de protección intrínseca similar al del bazo. (1)

Los que con más frecuencia metastatatizan en pene son los de vejiga, próstata, colon-recto y riñón, aunque además de órganos pélvicos próximos, ocasionalmente el origen son neoplasias viscerales a distancia.

En cuanto a la vía de diseminación de dichas metástasis, existe controversia, y se defienden tres: la diseminación

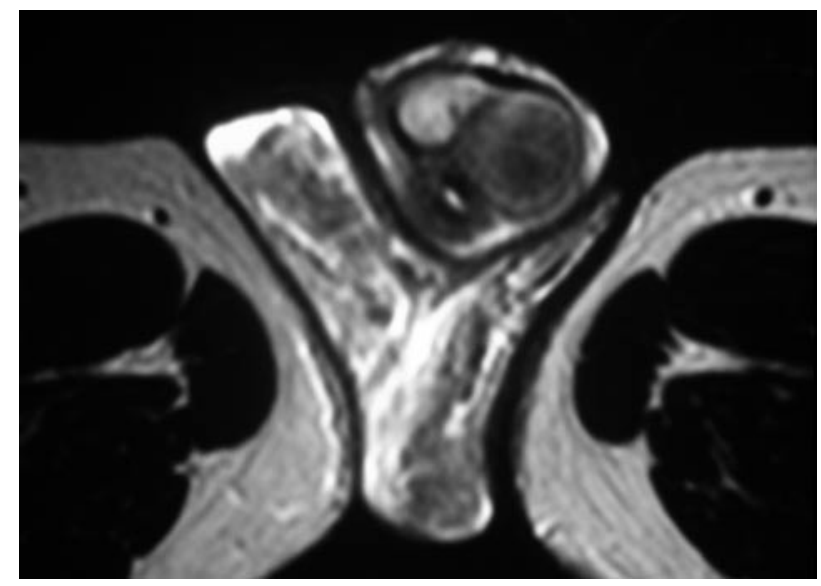

FIGURA 2. Imagen de un corte transversal de RM en la que se aprecia una masa que ocupa y expande el cuerpo cavernoso izquierdo, que por el realce en fase arterial del estudio con gadolinio es compatible con metástasis del carcinoma renal. 


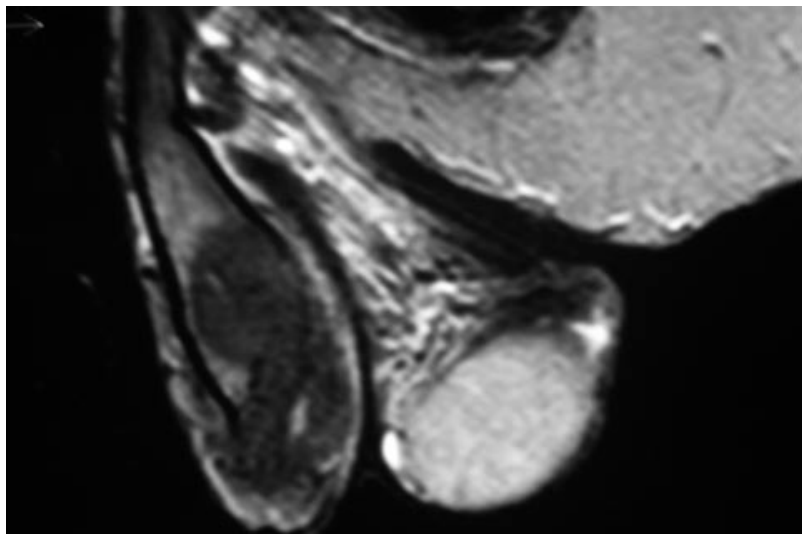

FIGURA 3. Corte sagital de RM del cuerpo cavernoso izquierdo en el que se aprecia una masa que lo ocupa compatible con la metástasis de un carcinoma.

hematógena por émbolos arteriales, las vías de retorno venoso o linfático retrógrado, y la vía de extensión directa, es decir, por contigüidad.

Clínicamente la forma de presentación más frecuente es el priapismo, aunque existen otras como nódulos o úlceras peneanas, tumefacción difusa, dolor o retención urinaria.

El diagnóstico se basa en la sospecha clínica y la exploración física, pero la confirmación viene dada por el examen microscópico de la biopsia o de la pieza de resección. El aspecto histológico más común de la invasión peneana es el reemplazo de uno o ambos cuerpos cavernosos por lesiones metastásicas, lo que explicaría la aparición frecuente de priapismo ("priapismo maligno"). Los depósitos cutáneos prepuciales o balánicos de células metastásicas, son menos comunes. Incluimos en el diagnóstico diferencial los tumores primarios de pene, chancro, chancroide, priapismo no tumoral, enfermedad de la Peyronie, tuberculosis y lesiones inflamatorias inespecíficas.

La presencia de metástasis en el pene ensombrece el pronóstico, ya que son una forma avanzada de tumor agresivo. Por lo general aparecen pronto tras el diagnóstico y tratamiento de la enfermedad primaria. En raras ocasiones transcurre un período prolongado entre el tratamiento de la enfermedad primaria y la aparición de metástasis en el pene, incluso existen descritos casos en los que el diagnóstico del tumor renal y la metástasis en el pene son simultáneos.

La aparición de dichas metástasis es evidencia de una enfermedad completamente diseminada y podríamos considerarlo como un estadio preterminal o terminal del paciente.

El tratamiento de estos pacientes, es otro tema controvertido, que depende de la localización, tamaño, estado general del paciente y sobretodo de la sintomatología clínica. Algunos autores defienden la penectomía total como procedimiento paliativo en pacientes con buen estado general $(7,8)$, en los cuales las metástasis sólo están confinadas al pene (3), aunque otros lo consideran como una opción demasiado agresiva. Otros han aconsejado la radioterapia asociada a la hipertermia en tumores localizados superficialmente $(2,4)$.

En nuestra opinión, llegado este punto, todo tratamiento que se plantea no debería tener más que una consideración paliativa, ya que no parece aumentar significativamente la supervivencia de dichos pacientes. Ante cáncer renal primario extirpable o ya intervenido y masa peneana única, podríamos plantearnos la exéresis local de la lesión, la penectomía parcial o la total, basándonos siempre, en la clínica del paciente y su alivio sintomático.

Como ya hemos dicho, las lesiones metastásicas del pene se asocian con la enfermedad avanzada, y por lo tanto, la supervivencia tras su aparición es limitada. Más del $65 \%$ de estos pacientes, presentan, en el momento del diagnóstico, metástasis en otras localizaciones.

La mayoría de los pacientes mueren en el período de un año tras este diagnóstico de enfermedad diseminada, como ocurrió en el caso que presentamos.

\section{BIBLIOGRAFIA y LECTURAS RECOMENDADAS (*lectura de interés $y^{* *}$ lectura fundamental)}

1. HERRERA PUERTO, J.; HERRERA FLORES, J.; LÓPEZ ELZAURDIA, C. y cols.: "Metástasis peniana de un carcinoma de células renales". Actas Urol. Esp., 589, 2002.

*2. MURO BIDAURRE, I.; ASPIAZU ARNAIZ, P.; ANTONIO RECARTE, J. y cols.: "Carcinoma metastático de pene: evaluación clínica, tratamiento y revisión de la literatura". Arch Esp Urol. 52, 9:994, 1999.

3. McINTYRE, I.G.; BURGESS, N.A.; ROBERTS, P.F.: "Penile metastasis from renal cell carcinoma". BJU. 77: 754, 1996.

*4. BEN-YOSEF, R.; KAPP, D.: "Cancer metastatic to the penis: treatment with hyperthermia and radiation therapy and review of the literature". J. Urol., 148: 67, 1992.

*5. PUPPO, P.; PERACHINO, M.; RICCIOTTI, G. y cols.: "Malignant priapism due to a huge renal carcinoma". European urology; 21: 169, 1992.

6. DANIELS, G.F.; SCHAEFFER, A.J.: "Renal cell carcinoma involving penis and testis; unusual initial presentations of metastatic disease". Urology 37: 369, 1991.

7. HADDAD, FS.: "Penile metastasis". Urology. 29: 464, 1987.

*8. MUKAMEL, E.; FARRER, J.; SMITH, RB. y cols.: "Metastatic carcinoma to penis; when is total penectomy indicated?" Urology. 24: 15, 1987.

9. ORDONEZ, N.G.; AYALA, A.G.; BRACKEN, R.B.: "Renal cell carcinoma metastatic to penis". Urology 19: 417, 1982. 